\title{
IETS OVER DE TAAL EN DE SPROOKJES VAN SURINAME
}

DOOR

\section{A. Donicie, C.s.s.R.}

Een kennismaking met de sprookjes van Suriname kan tevens een inleiding zijn tot de taal der Creolen in Suriname, het z.g. Neger-Engels.

Uit het contact van de geimporteerde slaven uit Afrika met de eerste kolonisten in Suriname, de Engelsen, en later met de Nederlanders, ontstond een mengtaal, algemeen bekend onder de naam van Neger-Engels. Deze benaming drukt echter taalkundig niet het juiste karakter uit van de Creolentaal in Suriname, omdat men zou kunnen denken, dat zij alleen maar bestaat uit een vermenging van Afrikaans en Engels, terwijl later men vooral is gaan creoliseren op basis van het Nederlands, zodat het Neger-Engels voornamelijk opgebouwd is uit drie elementen: Afrikaans, Engels en Nederlands. Ook vindt men in deze taal nog verschillende resten van het Portugees en het Frans, zeer zelden echter van het Duits. We zwijgen hier verder over het „,Saramaccaans," vroeger „Djoe tongo" geheten, dat alleen gesproken wordt door de Bosnegers van de Boven-Suriname en dat ontstaan is uit het contact van de slaven met de vroegere Portugese Joden.

Het Neger-Engels is in de eerste plaats een ,spreektaal” en de verbindingstaal tussen de vele rassen in Suriname, die alle min of meer Neger-Engels spreken en verstaan. De in het NegerEngels ,geschreven" werken zijn voor het grootste gedeelte niet afkomstig van de Creolen, maar van de Duitse zendelingen en Hollandse missionarissen. Een eigenlijk gezegde ,,geschreven” literatuur bezit het Neger-Engels dan ook niet, maar wel leeft er onder het Creolenvolk een schat van ,ongeschreven” literatuur, vastgesteld in een groot aantal sprookjes, die van mond tot mond in talloze variaties worden overgeleverd. Deze verhalen 
zijn niet alleen uit folkloristisch oogpunt van groot belang, maar geven ook taalkundig de beste kijk op de structuur van het Neger-Engels. HALL ${ }^{1}$ ) volgde dan ook een goede methode, door de bouw van het Neger-Engels op te trekken uit het sprookjesmateriaal, bijeengebracht door Herskovits ${ }^{2}$ ). Jammer genoeg is hij daarin minder goed geslaagd, maar de fout lag niet zozeer bij hem als bij zijn bronnen. We hopen daar nog eens op terug te komen.

De twee meest bekende verzamelingen van de Surinaamse sprookjes zijn die van de HERSKovitsen en van drvaNCAPPELLE ${ }^{3}$ ). Hier bieden wij de lezer enige sprookjes aan van de tot nog toe onuitgegeven verzameling van de bekende Pater W. AHLBRINCK die, voordat hij met de studie van de taal der Caraïben begon, zich voor het Neger-Engels interesseerde. In het jaar 1912 werden zij door hem opgenomen van de Creoolse vrouw: MARIA Helena Alexandrina Doffer, getrouwd met Lie-A-Kwie. Zij werd in 1846 in Paramaribo geboren en overleed in het jaar 1916 ook in Paramaribo. Deze sprookjes gaan dus reeds ver in het verleden terug.

Dr van CAPPELLE vermeldt in zijn boek nog twee andere verzamelingen, een van F. STÄHELIN ${ }^{4}$ ) en een van A. P. PÉNARD, die ik echter geen van beide heb kunnen raadplegen.

Typerend voor de Surinaamse vertellingen is $\mathrm{Sa}^{+}$do spin (anansi) er in veel gevallen als held optreedt, waaromheen dan, behalve de uitheemse olifant, vele Surinaamse dieren een rol spelen. Dr van Cappelle beweert zelfs (blz. 198), dat in de verhalen der Surinaamse negers de spin tien tegen één de heldenrol speelt. Maar dit is wat overdreven. In zijn eigen bundel komt anansi niet voor in 9 van de 35 verhalen, terwijl in de verzameling van AHLBRINCK de spin slechts in 4 van de 20 sprookjes de hoofdrol speelt. Als men deze twee bundels dus samen neemt, dan is de verhouding ongeveer gelijk: 30 anansi-tori's (verhalen) en 25 waarin de spin van het toneel verdwenen is. En ook bij HersKOviтs zijn er van de 148 sprookjes niet meer dan 70 eigenlijke spinverhalen. Wel is het waar, dat de verhalen, waarin de spin

1) Robert A. Hall: The linguistic structure of the taki-taki. Language 24,1948 , p. 92-116.

2) Melville J. Herskovits \& Frances S. Herskovits: Suriname folklore. Columbia Univ. Press, New York, 1936.

3) H. van Cappelle: Mythen en sagen uit West-Indië. Thieme, Zutphen, 1926.

4) Hessische Blätter für Volkskunde rgo8 en rgog. 
de hoofdrol speelt de oudste zijn en het meest karakteristiek, daar de spin de personificatie is van het negertype.

Op het gebied der Surinaamse sprookjes ligt nog een breed studieveld te ontginnen, met name in hoever de Surinaamse folklore ook Europese invloed heeft ondergaan en hoe zij Europese motieven heeft verwerkt. Reeds wees VOORHOEvE er op hoe het sprookje van Repelsteeltje in Suriname wordt teruggevonden en hier in een magische sfeer is getrokken ${ }^{1}$ ).

Spinverhalen worden er niet alleen verteld in Suriname, maar bij alle negers van de Westindische eilanden en van het vasteland van Zuid-Amerika. Wanneer men zoekt naar de herkomst van deze spinverhalen, dan is het spoor gauw gevonden. Waar in taal en cultus nog zoveel herinnert aan het oude Afrika, daar ligt het vermoeden voor de hand, dat deze verhalen door de negerslaven uit Afrika naar de nieuwe wereld zijn overgebracht. En zo is het inderdaad: vanaf de Senegal tot de Congo-rivier zijn deze spinverhalen in omloop. Maar men kan nog verder vragen : hoe komt het dat juist de spin de hoofdpersoon geworden is van zoveel sprookjes? Was de spin dan zulk een gewichtig dier? Inderdaad, reeds VAN CAPPELLE deelt ons mede (blz. 228), zonder vermelding van een of andere bron, dat volgens een overlevering aan de Goudkust het gehele mensdom van een grote spin afstamt. Maar aan 'spins waardigheid kunnen we niet meer twijfelen, wanneer we het citaat lezen, dat Lou LichTVELD ${ }^{2}$ ) aanhaalt uit het boek van Bosman: ,Deze spin noemen de Negers Anansee. Sy gelooven dat de eerste menschen van den zelven gemaekt zijn; en niet tegenstaende eenige door ommegang met de Blanken anders geleerd hebbende, so zijn 'er niet weinig, die by dat Geloof blijven, en welke waen haer niet uit 't hoofd te praaten is". En elders zegt hij: „Het getal der geener, welke gelooven, dat de Mensch door den Anansié, zijnde een groote Spin, geschapen is, is nog heden ten dage niet weynig, werdende zulks van zommigen noch hardnekkig gedreeven". Deze verering van de spin, als schepper der mensen, hebben de negerslaven met zich meegedragen naar hun nieuw vaderland en zo komt het, dat anansi nog altijd de hoofdpersoon is van een groot getal hunner verhalen.

1) J. Voorhoeve: Repelsteeltje in Suriname. Eldorado 2, 7/8, 1950, p. 95-96.

2) L. Lichtveld: Op zoek naar de spin. W. I. Gids jrg. I2, 1930, p. 209-230, 305-324.

3) Willem Bosman: Nauwkeurige beschrijving van de Guinese Goud-, Tand-en Slaven-kust. Daterend van vóór 1704. 
De spin hoorde in het verre verleden thuis in de mythe, onder de goden. Hoe hij langzamerhand van zijn goddelijke troon is gestoten en verhuisd naar het land der fabels, ofschoon nog verschillende van zijn goddelijke eigenschappen aanwijsbaar zijn in de Surinaamse sprookjes, hoe hij ten slotte zelfs zijn menselijke trekken verliest en weer gewoon dier wordt, hiervoor leze men de zeer interessante artikelen van LichTVELD.

Bij de Bosnegers heeft anansi zijn plaats onder de kinderen der goden nog behouden. Het is van groot belang dit vast te leggen, want tot nu toe bestonden hierover geen getuigenissen. Met Petrus Moesé sprak ik dezer dagen over anansi. Hij is een Saramaccaan van Godo, gelegen aan de scheiding van de Pikien Rio en Gran Rio. Twee jaar geleden uit het bos weggevlucht, werd hij door mij gedoopt en hij is een van de weinige bekeerlingen, van wie men veel los kan krijgen, dat betrouwbaar schijnt. Ik sprak met hem over de slimheid van anansi en vroeg hem hoe het komt, dat de spin zo slim is. Hij gaf toen het spontane antwoord: Onze oude mensen zeggen: „,Anansi a pikien foe gado, foe datti a koni so" (De spin is een kind van god en daarom is hij zo slim).

Wanneer worden de sprookjes verteld? Ongeveer dertig jaar geleden kwam het nog veel voor, 's avonds, voordat de kinderen gingen slapen, als de "ninne" (de bejaarde vrouw, dio do kinderen oppaste) of de moeder haar kroost om zich heen verzamelde en dan werd er verteld van koningen en prinsessen en van de streken van de spin. Maar die goede oude gewoonte bestaat reeds lang niet meer. Wel worden de sprookjes nog steeds voorgedragen door de houtkappers en de balata-bleeders om de lange avonden van het eenzame oerwoud wat te breken. Maar hun voortbestaan onder het volk danken de anansi-tori's vooral aan de dede-hoso's (sterfhuizen), waar het vertellen van spinverhalen tot het vaste ritueel der plechtigheden behoort. Tot nu toe gebeurt dat zelfs nog in de buitenwijken van de stad, maar in de districten is het bijna regel. Een veertig jaar geleden had men zelfs echte beroepsvertellers, die alle sterfhuizen afliepen en ,dede-hoso-lanteri's" werden genoemd (sterfhuis-lantaarns). De ouden van dagen in Paramaribo zullen zich nog kunnen herinneren: Swiet ba WeErie (William), Oom Zacheus, BA BeERTIE (Bertus). Zij vonden hun kost aan wat er opgediend werd bij de dede-hoso's, zoals scheeps- en broodbeschuit, anijsbollen, cacao, soms een dis van bananen en gezouten varkensvlees. Maar met dit beroep kan tegenwoordig de kost niet meer 
verdiend worden, ofschoon er ook nu nog prachtvertellers zijn, die men op ieder stẹrfhuis kan aantreffen. Ook bij de Bosnegers worden er op hun rouwfeesten nog altijd anansi-tori's verteld. Maar al staat het lijk soms weken boven aarde, ze mogen alleen verhaald worden op de avond van de dag der begrafenis, want, zoals Petrus Moesé mij vertelde: „Anansitori na kina foe jorká” (Anansi-tori is ,treef" of ,kina” voor de geest van de afgestorvene).

We zijn nu vanzelf gekomen bij de vraag, waarom de spinverhalen nog altijd op dede-hoso's voor de dag komen. Welk verband is er tussen anansi en de dood? Vanwaar het volksgeloof, dat spinverhalen niet overdag mogen verteld worden, tenzij na het uittrekken van een ooghaar ${ }^{\mathbf{1}}$ )? Vooraf zij gezegd dat dit volksgeloof zeer verzwakt is, zodat iedereen, behalve de Bosnegers, ze gemakkelijk voor je vertelt, ook bij dag en zonder een ooghaar uit te trekken. Zo hebben Prof. PÉE, JAN VOORHOEvE en ikzelve het vorige jaar verschillende sprookjes in Coronie kunnen vastleggen. Maar uit zichzelf zal iemand bij dag moeilijk een anansi-tori ten beste geven. En al gebeurt het dikwijls, zoals in Coronie, dat men iemand een zedeles wil meegeven in de verhaalvorm, dan zal men daarvoor vaak een spinverhaal gebruiken, maar de naam anansi niet uitspreken en deze veranderen in een onbepaald persoon, zoals ,,a man", de man. Er is ook niemand meer, noch in de stad noch in de districten, die het antwoord kan geven op de vraag, waarom de anansitori's alleen bij avond worden verhaald. Alleen onze Bosneger Petrus gaf mij een antwoord, dat van grote waarde is en waarmede tevens het verband tussen anansi en dood wordt gelegd. Hij zei mij, dat als iemand een anansi-tori bij dag vertelt, diens moeder zal sterven. Anansi is dus de veroorzaker van de dood, of kàn dat in ieder geval zijn. Als men zijn naam bij dag uitspreekt vallen er doden. Maar waarom dat niet bij avond? Waarom is dàn zijn dodelijke kracht verlamd? Het antwoord hierop wordt pas duidelijk als men de ontwikkelingslijn van de spin nagaat, zoals LichTVF.LD die geeft. De spin ressorteerde vroeger onder de goden. Maar zijn waardigheid heeft zich ontwikkeld van zonnesymbool naar zonnegod, schepper van de mensen en van veel op aarde. Dat zijn naam niet bij dag mag worden uitgesproken hangt hiermee samen, dat nog onbewust het geloof in de spin

1) De uitdrukking: Hari wan hai-wiwiri poeroe (een ooghaar uittrekken) heeft ook de figuurlijke betekenis van: Je overdrijft, je fantaseert, je liegt. 
als zonnegod voortleeft. Daarom mag zijn naam in zijn tegenwoordigheid zolang de zon schijnt niet worden uitgesproken, maar alleen bij avond, wanneer de zon is ondergegaan. Een analoog geval heeft men, wanneer men de zoela's (stroomversnellingen) overgaat. Een Bosneger zal nooit de naam van de zoela noemen, zolang hij ze niet gepasseerd is, want zou men de naam uitspreken in tegenwoordigheid van de zoela, dan zal de gado(god) van die stroomversnelling de boot doen zinken. Het ,hari wan hai-wiwiri poeroe" is dan een afweermiddel tegen het ijdel gebruiken van 'spins naam bij dag.

Dat anansi-tori's speciaal op sterfhuizen worden verteld, vindt zijn oorzaak hierin, dat zij ,,kina foe jorka" zijn: zij dienen dus als afweermiddel, om de jorka op een afstand te houden, zodat hij geen kwaad meer kan doen. Nog twee andere Bosnegers van Granman-kondre (Boven-Suriname) heb ik zijdelings vragen gesteld over anansi. $\mathrm{Zij}$ legden alle twee een grote vrees aan de dag voor anansi, want zo zeiden zij: „Ai kiri alla meti foe boesi" (Hij doodt alle dieren van het bos). En ook zij getuigden: „Anansitori a trefoe foe jorka”. Wat betreft het vertellen van anansi-tori's bij dag kreeg ik hetzelfde antwoord: „Dan zal je moeder sterven".

We zien dus, dat de spin nog voortleeft in zijn hogere qualiteit van ,,godenkind” (pikien foe gado) en in zijn ,,pejorative Deutung" van veroorzaker van de dood. Maar zeer merkwaardig is het, dat anansi tot nu toe gekend wordt, al is het misschien onbewust, als schepper der mensen, of beter gezegd als verwekker van kinderen. Niet lang geleden was ik op een erf in gesprek met een oude vrouw. Toevallig valt er een spin uit de boom op haar hand. Ze sloeg de spin weg en zeide: „Anansi, libi soema nanga law, mi grani kaba!" (Anansi houd op met je gekheid, ik ben al oud). Ik kan geen kinderen meer krijgen, wilde zij zeggen. En een jonge vrouw zal in een dergelijk geval de spin niet wegslaan en zeggen: „Ai anansi, kom, ja anansi kom maar”. Talloos zijn bovendien in dit verband de minder nette toespelingen, wanneer een spin op een manspersoon valt. In zijn hoedanigheid van verwekker van kinderen is anansi tevens geluksbode.

De Surinaamse sprookjes worden niet in één ruk voorgedragen en uitverteld, maar op vaste momenten onderbroken door gezangen van de ,kotsiengi-mannen”. Zij worden zo genoemd, omdat zij ,het verhaal afbreken" (koti a tori) door hun lied (siengi). Ieder omstander is vrij dit te doen en in een bekend verhaal loeren zij op het begin van de verschillende bedrijven 
om hun gezangen aan te heffen. Maar op een meer geregelde vertelavond nemen de verhalers hun kotsiengi-mannen mee, die zij van te voren instrueren, waar en met welk gezang zij moeten onderbreken.

Om een idee te geven van een anansi-toriavond, hoe men zich er op voorbereidt, hoe scherts en ernst daarbij afwisselen, hoe de sprookjes worden ingezet en onderbroken, geven wij de beschrijving weer van de bekende Surinaamse onderwijzer W. Campagne. Hij was zo goed om de indrukken die het optreden van de eens bekende verteller BA ЈонN op hem maakten, op schrift te stellen. We geven hier letterlijk zijn relaas weer.

$\mathrm{Ba}$ John is reeds jaren dood. Niemand heeft hem de eer gegeven, die hem toekwam. Hij was een eenvoudig man, arm en onbekend. Maar voor ons in de kleine achterbuurt was hij een held, een knap man, een kunstenaar. Lezen en schrijven kende hij niet, maar zijn geheugen was buitengewoon ontwikkeld. In het vertellen van eigenlijke anansitori's was hij niets. Hij kende en vertelde geschiedenissen uit „Duizend en één nacht". Weet je wat dat is? vroeg hij altijd aan zijn toehoorders. Duizend en één dag heb ik nodig, om je te vertellen al de verhalen uit dat grote boek, dat verloren is gegaan.

$\mathrm{Ba}$ John zou een avond gaan vertellen op ons erf. De buurt wordt gewaarschuwd. Oud en jong bereidt zich voor op de verhalen van $\mathrm{Ba}$ John. Centen worden gebedeld. Koren (mais) wordt gebakken tot soekrirtji, suikererwtjes, of gemalen asogri; cassave bereid tot brood. Ook wordt er gezorgd voor een stoop jenever voor Ba John en de helpers. De hele buurt weet, dat er een genotvolle avond op komst is. Banken, stoelen, kisten worden aangedragen. Iedereen tracht een goede plaats te bemachtigen. Het erf is vol. Een groot vuur is in het midden aangelegd. Als het hout tot kool is verbrand, warmt de één zijn cacao daarop, anderen stoppen geschilde bananen onder de as, om ze te roosteren. Wat zal er verteld worden? Na enige tijd verschijnt Ba John. Om de belangstelling op te wekken vertelt hij eerst enige ,,laitori's" (raadsels). A langa na fesi a langa na baka (Het is lang van voren en lang van achteren). Antwoord: een straat. De belangstelling is gewekt. Iedereen verlangt nu naar het verhaal. Maar Ba John is zich bewust van zijn waarde. Je krijgt hem zo maar niet aan het vertellen. „,Beginnen jullie eerst maar," zegt hij. Daar staat Soekim (Joachim) op. Hij vertelt niet van de spin, maar van de lotgevallen der slaven. Hoe hingen wij aan zijn lippen, als hij ons vertelde, hoe de hele slavenmacht van een plantage dicht bij Georgetown, de eigenaar fopte gedurende een feest en er van door trok. Na dit spannend verhaal voelt Oom Djani, dat zijn beurt gekomen is. Hij zal de spin voor het voetlicht brengen. Hij begint: „,Kri kra, alla man na hem kraka?”' Een waarschuwingsteken: „Let op, is ieder op zijn post?" „A sa go"? (Zal het gaan ?) vraagt hij. ,,A sa go" (het zal gaan), roepen de toehoorders. Dan volgt de stereotype inleidingsformule van bijna iedere anansitori : ,Ir tien-tien, wan mooi wentje ben de" (Heel lang geleden was er eens een mooi meisje). Zij was zeer wispelturig. Iedereen trachtte dit meisje met haar schatten aan de haak te slaan: prinsen, baronnen, zelfs de zoon van de gouverneur. Maar telkens liet zij weten, dat zij niet thuis was. 
Nauwelijks was Oom Djani tot hier gekomen met zijn verhaal of daar roept er één:, ,Bato, dan na mi tori joe dé go taki" (Stop, je gaat daar juist mijn lievelingsverhaal vertellen), en hij heft, bijgestaan door, anderen, zijn eerste kotsiengi aan:

Mies Helena, mies Helena trien tran trien, mi na moni masra, trien tran trien". (3 keer) (Juf Helena, juf Helena trien tran trien, ik ben een man van geld, trien tran trien.)

Hoor, daar roept een ander: „Oen stem froestoe” (Onze stem is roestig) en de jenever wordt aan de zangers gepresenteerd.

$\mathrm{Nu}$ mag de verteller doorgaan. Hij beschrijft de rijkdommen van het meisje, haar stugheid enz. Hier onderbreekt iemand het verhaal met zijn lied: „Schoon Helena onder de zon”.

Anansi zal nu zijn kans wagen. Eerst een advertentie in de krant: „Ba Anansi komoppo na Akademi. San professor no sabi, anansi sabi. A tron bigi datra, a de dresi alla sanni". (Broer Spin is van de Academie gekomen. Wat professor niet weet, dat weet Anansi. Hij is een groot dokter. Hij geneest alles).

De verteller gaat verder. Maar voordat hij de verdere plannen van spin verhaalt, wordt hij al weer onderbroken met een ander lied:

„,Ba Anansi mooi man, na mi de sopo den oema”. (Ba Anansi de mooie man, ik houd de vrouwen voor de gek).

Het meisje leest de advertentie en wil graag kennis maken met de beroemde dokter. $Z_{\text {ij }}$ stuurt haar knecht met een uitnodiging naar de dokter. Anansi in zijn schik. Hij naar een rijke vriend: Man, er is geld te verdienen! Bouw me een mooie vier-riemse vissersboot, maak mij een deftig pak met krakende schoenen en hoge hoed en handschoenen. De rest komt in orde en je krijgt je geld dubbel en dwars terug.

Een kotsiengi-man staat op en beschrijft de pracht en praal door anansi ten toon gesteld en demonstreert de gang van de boot met zijn:

„,Ba Anansi mooi man grienja, ba Anansi mooi man grienja”.

(,Grienja” een klanknabootsing, geeft het rhythme van de armen en roeispanen aan.) Sommigen bootsen het roeien na.

„,Baas, go dorro manga joe tori” (Baas, ga door met je verhaal), roept de kotsiengi-man. En de verhaler beschrijft verder het huwelijksfeest en de ontnuchtering later.

Weer staat een kotsiengi-man op en zegt: , Jullie kent allemaal het verhaal van het andere meisje met aboma". Hij begint te zingen:

„,Mi mama, mi papa kom jepi mi, aboma de swari mi”. (Mijn moeder, mijn vader, kom mij helpen, de boa wil me opslikken).

Als dit verhaal uitgezongen is, staat Oom Djani triomfantelijk op kijkt naar de toehoorders, neemt een flinke teug van de jenever en zegt: „,Mi tori habe ala soeba-soeba, ai opo joe porion". (Mijn verhaal heeft alle mogelijke vermaken, het geeft je spirit, het maakt je poriën open). Oom Djani gaat weer zitten, zijn tori is geëindigd.

Een tweede verteller staat op en verhaalt, hoe Ba Anansi zijn vrouw Sa Akoeba fopte en de kalkoen met zijn vrienden opmaakte. Een derde geeft een verklaring, waarom anansi in de hoeken en beslagruim- 


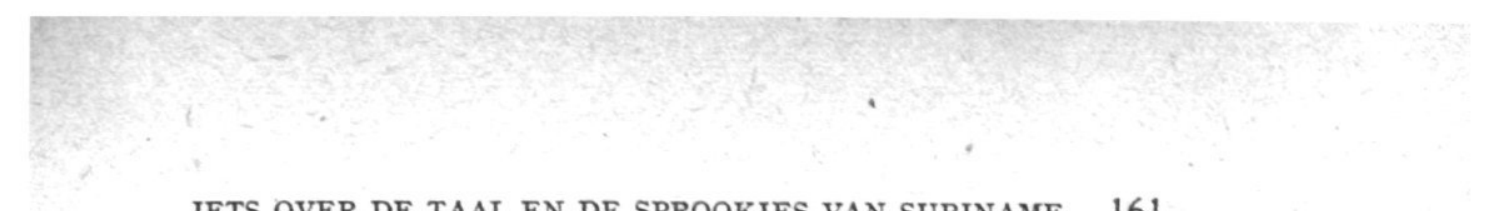

IETS OVER DE TAAL EN DE SPROOKJES VAN SURINAME

te $\left.{ }^{1}\right)$ leeft. Er is stemming. Ba John ziet het. Hij treedt naar voren. Hij zal ons vertellen uit zijn Duizend en één nacht-boek, dat hij zelf nooit gelezen heeft. Aller ogen zijn op hem gericht: Wat ik ga vertellen, zegt hij, handelt over de trouw van twee vrienden, Frederik en Willem, en over de invloed, die de vrouw op de man kan hebben. Wie zijn ogen niet kan bedwingen doet beter op te staan en zich te verwijderen, want Uw tranen zullen de grond besproeien. Wie weekhartig is, wordt ook verzocht om weg te gaan, want ik wens niet gestoord te worden door het wel en wee en het zuchten.

Hij ging zitten; alles is muisstil; zijn haren glanzen in de rose schijn van het vuur. Hij vertelt zo schoon. Nu eens vermanend, dan weer gebiedend of zalvend. Hij beleeft zijn verhaal zozeer, dat de tranen hem over de wangen rollen. En een ieder gaat peinzend naar huis, als Ba John zijn verhaal eindigt met de les: Als de vrouw goed is, is de man ook goed.

Ba John vertelde geen anansi-tori's; hij was de man van de ,,ondrofinni-tori's", van de parabels, die de mensen een goede les meegeven. Ook zijn verhaal werd onderbroken, maar met ernstige en stichtende siengi's. En dit gaf een heel andere omlijsting aan het geheel. - Tot zover de heer CAMPAGNE.

Niet altijd gaat het er op vertelavonden zo plezierig en onschuldig toe, als boven is beschreven. Vooral op de dede-hoso's worden soms de grofste anansitori's verteld, want anansi kan een flinke scheve schaats rijden. Tegen deze ontaarde verhalen hebben de kerken hier dikwijls geageerd, maar nooit tegen de anansi-tori's ut sic, zoals wel eens geïnsinueerd wordt.

Om het eenvoudige en kinderlijke in de sprookjes te kunnen proeven, is het gewenst iets over de taal te vertellen. Tot onze spijt kunnen we de lezer nog geen tekst aanbieden, die phonetisch-wetenschappelijk verantwoord is. In de schrijfwijze van AHLBRINCK konden we natuurlijk moeilijk veranderingen aanbrengen. Wat de klankleer betreft willen we alleen opmerken, dat bijna alle woorden in het Neger-Engels uitgaan op een klinker, hetzij wel, hetzij niet genasaliseerd. Als nasaal-teken wordt in de tekst gebruikt de klank $m$ of $n$, tenminste op het eind van een woord. De 1 en $r$ wisselen zeer dikwijls. De $g$ wordt uitgesproken als in het Frans. De h komt niet voor, tenzij soms om een gevoelswaarde uit te drukken. Ook de klank v kent het Neger-Engels niet, evenmin de $z$, tenzij misschien in een of twee woorden. De $\mathrm{g}$ en de $\mathrm{k}$ worden vóór een $\mathrm{i}$ gewoonlijk gepalataliseerd tot $\mathrm{dj}$ en $\mathrm{tj}$.

Het klinker-systeem is zeer eenvoudig. Het Neger-Engels kent de korte a-klank van het Hollandse ,nat"; de korte i van ,pit"; de korte o van ,ppot". De e-klank van het Hollandse ,,bed” bestaat niet. Alle klinkers komen ook genasaliseerd voor. Verder heeft het Neger-Engels ook de oe-klank van het Hollandse ,,voet”. De lange a-klank ontbreekt. Wel bestaat de lange ee en oo-klank en de lange ie. Als tweeklanken komen voor: ai, aw, eej, oi, oow. In de tekst worden aw en oow voorgesteld door au en ou.

1) Onder beslagruimte wordt verstaan: een ruimte tussen de planken in de betimmering van een huis.

West-Indische Gids XXXIII 
Wat vormleer en syntaxis betreft het volgende:

Het Neger-Engels heeft geen onderscheid tussen enkelvoud en meervoud; de meervoudsuitgangen ontbreken. Het pluralis wordt evenals in het Neger-Hollands ${ }^{1}$ ) en hêt Neger-Frans ${ }^{2}$ ) gevormd door het persoonlijk voornaamwoord van de derde persoon meervoud, bv. dagoe, hond; den dagoe, zij honden (de honden).

Slechts enkele woorden bestaan er om het natuurlijk geslacht aan te duiden, zoals: krabita, geit; boko-boko, bok. Gewoonlijk wordt dit omschreven door de woorden ,man" of ,,vrouw"; bv. man-pikien, man-kind(zoon); oema-pikien, vrouw-kind (dochter). Soms wordt zelfs „man" gebruikt om het vrouwelijk geslacht aan te duiden; bv. nai-man, naaister.

De pronomina personalia en possessiva zijn niet onderscheiden. Alleen voor het persoonlijk voornaamwoord van de derde persoon enkelvoud $(\mathrm{a}=\mathrm{hij})$ en eerste persoon meervoud (wi $=$ wij) heeft men een bijvorm ,hem" en ,,oen". Ook het ,,patois" van Frans-Guyana kent geen verschil tussen deze twee soorten pronomina, tenzij in de derde persoon enkelvoud ${ }^{3}$ ).

Het werkwoord kent geen vervoeging; de tijden worden gevormd door de hulpwerkwoorden van ,,zijn".

Ook worden de woorden niet verbogen, zodat de naamvallen op een andere manier moeten worden aangeduid. Dit gebeurt door bepaalde woordschikking of door omschrijving van werkwoorden. De gewone woordschikking is: subject, verbum, object. De genitief wordt uitgedrukt door vooraanplaatsing, bv. mi mamà fouroe, mijn moeder kippen (de kippen van mijn moeder). Men gebruikt echter ook de praepositie „,foe”, bv. den fouroe foe mi mamà.

De datief wordt omschreven door het werkwoord ,,geven" (gi), bv. tjari a nefi kom gi mi: Breng het mes, kom, geef mij (Breng mij het mes).

Ook de plaatsbepalingen worden zonder uitzondering omschreven met het werkwoord ,,zijn”' (na), bv. na hoso baka, zijnde huis rug (achter het huis). Het locaal nomen, dat voor plaatsbepaling fungeert, kan zowel achterop als voorop geplaatst worden, bv. na baka hoso. Tegenwoordig komt ook de vorm voor: na baka foe a hoso.

Nog heel veel andere bepalingen worden werkwoordelijk uitgedrukt. Hiervoor komen vooral in aanmerking de werkwoorden ,,teki” (nemen) en ,"meki" (maken).

Zij kunnen voor bijna alle Hollandse praeposities fungeren, bv. Gado teki doti, meki Adam skien: God nam aarde maakte Adams lichaam (God maakte het lichaam van Adam uit aarde.) Siki meki a kom mangri so: Ziekte heeft gemaakt, dat hij zo mager is geworden.

Zelfs een voor onze begrippen enkelvoudige handeling wordt in al

1) D. C. Hesseling: Het Negerhollands der Deense Antillen. Leiden, 1905.

$\left.{ }^{2}\right)$ Jules Faine: Le Créole dans l'univers. Port-au-Prince, Haïti, 1939. Bv. zouézeau llo, dat is: les oiseaux. De derde persoon meervoud van het persoonlijk voornaamwoord is ook ,llo"; FAINE is echter deze overeenkomst niet opgevallen.

3) M. Auguste Horth: Le patois Guyanais. Impri merie Paul Laporte, 1949. 
haàr bewegingen ontleed en omschreven door meerdere werkwoorden. Bv. go teki a boekoe, tjari hem kom gi mi, ga neem het boek, breng het, kom geef mij.

Typerend voor het Neger-Engels zijn ook de vele verdubbelingen. Zij kunnen voor bijna alles dienen; om intensivum en frequentativum uit te drukken; om het meervoud te vormen; om nomina en adjectiva van werkwoorden te maken, enz. bv. hari, trekken; hari-hari, trek-trek (hark); poisi, puist; pois-poisi, puisten; hesi, snel; hees-hesi, zeer snel; firi, voelen; firi-firi, betasten.

Ook het onderscheid der woordsoorten is in het Neger-Engels zeer vaag. Een en hetzelfde woord kan dienen voor zelfstandig naamwoord, werkwoord, bijwoord, bv. na kaba foe a strati, het einde van de straat; joe moe $k a b a$ joe wroko, je moet je werk afmaken; mi njam $k a b a$, ik heb al gegeten.

Uit dit beknopte overzicht zal het iedereen wel duidelijk zijn, dat het Neger-Engels een heel andere structuur ${ }^{1}$ ) heeft dan de Westeuropese talen, en dat de categorieën van deze talen al heel slecht in zijn schema passen.

Maar ook zal een ieder moeten toegeven, dat juist door deze analytische structuur van het Neger-Engels het zeer moeilijk is een bevredigende vertaling te leveren. Deze moeilijkheden worden nog vergroot, door wat men zou kunnen noemen de stylistische karaktertrekken van het Neger-Engels. Zo zijn opvallend de vele herhalingen, zoals herhaling van het zelfstandig naamwoord in plaats van het persoonlijk voornaamwoord (vgl. in , De gans en het meisje”, waar in de drie eerste zinnen reeds vier keer het woord ,,mama” wordt gebruikt); van de andere kant herhaling van het persoonlijk voornaamwoord in plaats van het voegwoord (vgl. A si wan gansi a srikki: $\mathrm{Zij}$ zag een gans zij schrok, waar wij zouden zeggen: zij zag een gans en schrok); herhaling van hetzelfde woord in plaats van een synoniem (vgl. in ,,De hond en de lever” de tweede alinea, waar drie keer het woord ,,teki" gebruikt wordt).

Als eigenaardigheid moet hierbij ook worden opgemerkt het weglaten van het lidwoord bij de hoofdpersonen in de sprookjes.

Van taalkundig oogpunt uit bezien is die vertaling de beste, waarin het primitieve en kinderlijke en vooral het analytische karakter van het Neger-Engels het meest tot zijn recht komt, een zoveel mogelijk letterlijke vertaling dus. Van dit standpunt uit is het sprookje van „,De spin, de hond en de lever" vertaald. We brengen hierbij dank aan de heer Lichtveld, die dit sprookje voor ons nakeek en verbeterde. Wat in dit sprookje tussen haakjes is geplaatst, staat niet in de NegerEngelse tekst.

Het eerste sprookje is iets vrijer vertaald; er is minder rekening in gehouden met de stylistische karaktertrekken van het Neger-Engels.

Ten slotte zij nog opgemerkt, dat het sprookje van ,,De spin, de hond en de lever" ook reeds bij Herskovits en van Cappelle te vinden is. We hebben er geen bezwaar in gezien ook dit te vertalen, daar wij im-

1) Vergelijk voor een uitvoerige beschrijving van de structuur van het Neger-Engels (de beste studie op dit gebied) Lou Lichtveld: Afrikaansche resten in de Creolentaal van Suriname. W.I.Gids jrg. Io, 1928 , p. 391-402, 1929, p. 507-526; II, 1929, p. 72-84, 251-262. 
mers ook een beeld van de taal willen geven. In de tekst van AHLBRINCK ontbreekt de ,"moraal" op het eind van dit verhaal, die VAN CAPPELLE wel geeft: , Al ben je nog zo slim, toch kan je nog wel eens worden beetgenomen".

Laten we nu overgaan tot de tekst en vertaling.

Alla soema na hem kraka?

A tori sa go?

$$
\text { A sa go. }
$$

Paramaribo, najaar 1951.

\section{(De Gans en het Meisje)}

Ir tien tien ${ }^{1}$ ) wan mama ben de ${ }^{2}$ ), a ben habi wan oemapikien. A mam ben de wassi krosi gi ${ }^{3}$ ) den matrosi. Wan matrosi a 'ma ben sabi boen, disi ben de kom foeloe na da ${ }^{4}$ ) mama. Di a matrosi de go gowe nanga sipi, a aksi a pikien, san a sa wanni meki a tjari gi hem, te a de kom bakka. A pikien takki: ,,Mi wanni wan braka blomitji." A matrosi aksi hem, effi a no wanni noti moro; a takki, nono. A matrosi takki: „,We, a boen, mi sa soekoe hem gi joe." A aksi a 'ma, san a wanni; a 'ma takki: ,,ibriwan sanni ${ }^{5}$ ), di joe kan finni." A matrosi takki adjosi, a gowe.

Di a doro na wan kondre, a go soekoe, san a kan finni foe bai gi a mama; a finni wan mooi blomkipatoe, ma a no finni na brakka blomitji. A sari so te, die a no kan finni hem. Ma di den de kom bakka ${ }^{6}$ ), a si wan brakka blommitji, di de gro na sei liba. A aksi foe na sipi tjari

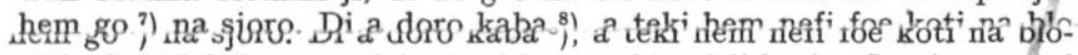
mitji. Soleki $\mathrm{fa}^{9}$ ) a wanni foe koti hem, a blomitji bari: ,San joe wanni nanga mi ?" A matrosi takki: ,Na wan soema begi mi, foe soekoe wan braka blommitji gi hem." A blommitji takki: , Joe kan broko mi, ma joe moesoe ferteri na soema, takki ${ }^{10}$ ) mi takki, datti di a wanni mi, a moesoe teki alla sanni, di sa kom na hem tappoe."

A matrosi pramisi, takki a sa doe datti.

1) ir tien tien, eens; de stereotiepe inleidingsformule bij de sprookjes

2) de, zijn; ben de, voltooid verleden tijd van zijn

3) gi, geven; 't werkwoord ,,geven" wordt gebruikt, om de datief uit te drukken

4) $d a$, bepalend lidwoord; komt alleen in de schrijftaal voor; in de spreektaal is dit na of $a$

s) ibriwan sanni, letterlijk: ieder ding

6) letterlijk: toen zij aan 't terug komen waren

7) tjari go: beweging van spreker af wordt met go uitgedrukt; naar de spreker toe met kom, bv. tjari hem kom dia, breng hem hier

$\left.{ }^{8}\right)$ kaba, betekent ,,klaar" of ,,reeds"; wordt ook gebruikt om de voltooid verleden tijd uit te drukken

$\left.{ }^{9}\right)$ soleki fa, letterlijk: zoals hoe; de gelijktijdigheid van twee handelingen wordt uitgedrukt door: soleki fa of alleen door: $f a$

10) takki, zeggen; 't Nederlandse voegwoord ,dat" wordt gewoonlijk door takki uitgedrukt, soms door datti 
Di a doro na hem kondre, a tjari na blommitji gi a pikien, a ferteri hem san a blommitji takki. A pikien skreki, ma a teki hem tokkoe. A poti hem na ini hem sribikamra na tapoe hem ${ }^{1}$ ) fensri. Neti di a go sribi a opo hem fensre, so leki fa ${ }^{2}$ ) a gewenti. Soleki fa ${ }^{3}$ ) a go didon, a jeeri wan sanni de frei. A opo loekoe, san datti - a si wan gansi a skreki. A gansi trom wantron wan konoepikien, dan a takki: ,No skreki, denki san joe ben pramisi." A takki tori so te $\left.{ }^{4}\right)$ nanga hem te twaalfoe joeroe, dan a tron wan gansi bakka, a frei gowe. A so ${ }^{5}$ ) a gansi de kom alla neti, te a de go trow nanga hem.

Di wan tanta foe na meisje kisi foe jeri, takki a de go trow, a go wan dei na hem. Di na mama foe na meisje si a tanta, a takki: „San joe kom doe dia, di mi ben de poti, joe no ben kom soekoe mi." A tanta takki: „,No loekoe so ba!" A tanta tan heeri dei, ma a no si na soema, di a pikien de go trow.

Wan tra dei, a tanta senni hem pikien foe go tan nanga hem tanta. A pikien tan heeri dei nanga hem tanta, neti a tan sribi toe. Hem mama ben takki gi hem, datti a moesoe aksi foe sribi nanga hem sisa, bikassi a ben moesoe loekoe, effi soema no de kom na hem sisa ${ }^{6}$ ). Di neti kom a pikien aksi foe go sribi naga hem sisa. A meisje meki wan presi ${ }^{7}$ ) gi hem na fesi hem beddi. Te foe na gansi kom, a pikien sribi kaba. Mamantem a pikien wiki, dan a go na hosso. A mama aksi hem, san a si; a takki; ,Noti mi no si, bikassi mi sribi." A mama hatti bron ${ }^{8}$ ) nanga hem, a kosi hem so te.

Wan tra dei a tanta senni wan tra pikien foe go tan nanga hem sisa, a taki gi hem: ,Joe moesoe aksi foe sribi na sei joe sisa," A pikien go, a takki gi hem tanta, datti a de tan sribi te neti. Neti a pikien aksi foe sribi na sei hem sisa. A meisje poti hem na ini hem beddi. A pikien ben tjari wan pisi natti krosi $^{9}$ ) nanga hem; ibritron te sribi de kiri ${ }^{10}$ ) hem, a de teki na krosi figi hem hai. A so a pikien tan na hai $\left.{ }^{11}\right)$, te a si na gansi kom. A jeere alla sanni, di a gansi takki nanga hem sisa. Mamantem a pikien wakka hesi hesi ${ }^{12}$ ) go ferteri hem mama, san a ben si. Di a mama jeeri datti, a go na smitti foe a kan meki ${ }^{13}$ ) wan isri pentji gi hem.

1) hem, letterlijk: haar venster

2) letterlijk: zoals zij gewoon was

3) zie noot 9 op vorige bladzijde

4) so te, drukt een intensivum uit, hetzij van tijd, hetzij van graad

5) a so, letterlijk: 't is zo; 't N.E. heeft twee werkwoorden voor , ,zijn"

nl. de en $n a$ of $a ; n a$ is a-temporeel

6) sisa, letterlijk: zuster

$\left.{ }^{7}\right)$ presi, plaats: heeft ook een speciale betekenis van een slaapplaats op de grond

$\left.{ }^{8}\right)$ hatti bron, haar hart brandde; de gewone uitdrukking voor , kwaad worden"

$\left.{ }^{9}\right)$ letterlijk: een stuk nat goed

10) sribi kiri hem, slaap doodt haar

11) tan na hai, bleef zijnde oog

12) hesi-hesi; de verdubbeling duidt hier een intensivum aan

13) foe a kan meki, letterlijk: of hij kon maken 
A go wan mofoneti ${ }^{1}$ ) go poti na pentji leti pe na gansi de sakka sidon. A pikien nanga a mama no sabi, takki a so wan sanni drape.

Neti, di a gansi de frei kom, soleki fa a wanni sidon a pentji soetoe hem na ondre hem bere. Wantron a gansi gowe bakka; a siki foe dede ${ }^{2}$ ). Di a meisje si, datti na gansi no de kom, a denki, takki, san sa doe hem ${ }^{3}$ ).

Ma te foe mamantem ${ }^{4}$ ), a tanta kom poeroe na pentji. A meisje wakti so meni neti, a no si gansi de kom. A takki gi hem mama: „Mi mama, mi de go soekoe hem".

A meisje wakka, a wakka so te, te a kom weri; a si wan bom, dan a go sidon na hem ondro foe blo pikienso. Di a sidon drape, a jere mati sekrepattoe de takki gi mati kakalakka, takki: „Konoepikein de siki ogri, a wan meisje hosso a go, dan den poti ${ }^{5}$ ) wan pentji meki a soetoe hem. Someni datra loekoe hem kaba, ma ete a no man kom betre! Ma mi sabi wan dresi, di kan meki hem kom betre."

Mati kakalakka aksi: ,We, soortoe dresi da datti?”

Mati sekrepattoe takki: ,Joe de teki dri wiwiri foe na bom disi nanga didibri tere bron meki a kom tron wan poeiri ${ }^{6}$ ) dan joe teki hem lobi ${ }^{7}$ ) hem na konoepikien ondrobere."

Di a meisje jeri datti, a opo safri, brokko dri wiwiri foe, na bom, sondro datti mati skrepattoe nanga mati kakkalakka si hem. A go na ini wan koleisi, a aksi faja, dan a bron na wiwiri nanga da didibritere. Di a kaba foe datti, a teki papira fow hem leki poeiri. A meisje go bai wan broekoe nanga wan jas, dan a wiri hem. A joeroe wan sjeesi, a rij nanga a sjeesi pasa na fesi na doro ${ }^{8}$ ) foe konoehosso.

Di a konoe jeeri, takki wan njoen datra de pasa, a senni kari ${ }^{9}$ ) hem. Wantem a datra go na ini, a loekoe konoepikien, dan a gi hem na poeiri. A dei na bakka, a kom loekoe hem bakka, a si, takki a de sakka. Te foe dri dei konoepikien kom betre. A aksi na datra homeni a moesoe pai hem, a datra takki: , Joe no ha ${ }^{10}$ ) foe pai mi - gi mi wan sakkaanjisa, pe joe nem marki nanga wan fingalinga." Ma konoe ben wanni gi hem moni tokkoe, alwasi a no ben wanni hem. Ma hosan konoe doe, a no teki datti. Konoepikien gi hem wan linga. A teki disi, dan a go hesi-hesi bakka na hem hoso. A joeroetem a doro na hoso, a ferteri hem mama, hosań pasa. A mama prisiri foe jeeri, takki konoepikien kom betre kaba.

Neti di a meisje go foe sribi, a jeri na gansi de frei kom. A joeroetem a gansi kom, a takki: ,Na datti na da paiman ${ }^{11}$ ), di joe de gi mi; joe ben denki, takki mi sa dede, ma mi kom betre kaba." A meisje aksi hem, san ben doe hem. A ferteri hem takki na wan pentji, di a ben poti na

1) mofoneti, letterlijk: de mond van de nacht

2) letterlijk: ziek, om dood te gaan

3) letterlijk: dacht zij zeggend, wat zal hem doen

4) te foe mamantem, te mamantem, mamantem = 's morgens

5) poti meki a soetoe hem, plaatste een pen, laat hem steken

6) letterlijk: verbrand ze, laat ze komen veranderen een poeder

$\left.{ }^{7}\right)$ teki lobi, letterlijk: neem en smeer

8) na fesi na doro, vóór de deur

9) senni kari, zond, om hem te roepen

10) $h a$, afkorting van $h a b i$

11) na datti na da paiman, 't is dat, zijnde de beloning 
tappoe na fensre ben soetoe hem. A meisje kisi wantron na hem prakseri, takki na hem tanta ben poti na pentji. A gansi no wanni foe jeri noti foe na meisje moro, a wanni gowe. Ma di a wanni gowe, a meisje aksi hem: ,,We, joe sabi, soema dressi joe ?” A gansi takki: ,Na wan datra." Dan a meisje piki: „,Na mi srefi-srefi ${ }^{1}$ ) wan dresi joe.” Ma a gansi no wanni bribi datti.

Di a no wanni bribi, a meisje teki na fingalinga nanga hem sakkaanjisa sori hem. A joeroetem a gansi si, takki na foe hem, a skreki. A meisje ferteri hem, fa alla sanni wakka. Di a jeri datti, a si, takki na meisje de wan boen meisje. A gansi tan takki tori nanga hem te twaalfoe joeroe, dan a gowe bakka.

Di a doro na hoso, a ferteri hem papa, soema ben de na datra, di ben dresi hem. Konoe takki wantron, datti a moesoe trow nanga hem. A gansi tron wantem wan libisoema. A trow nanga na meisje, heri moen den firi feesti. A meisje teki hem mama kom libi nanga hem. ${ }^{2}$ )

Dan na so na tori kom kaba.

\section{Vertaling van \\ De Gans en het Meisje}

Er was eens een moeder. $\mathrm{Zij}$ had een dochter. De moeder deed de was voor de matrozen. Een van de matrozen, die dikwijls bij de moeder kwam, kende zij goed. Toen de matroos op 't punt stond met de boot te vertrekken, vroeg hij het meisje: ,Wat zou je graag willen, dat ik voor je meebreng, wanneer ik terugkom?" 't Meisje antwoordde: ,Ik zou graag een zwarte bloem hebben". De matroos vroeg haar, of zij niets anders wilde. Zij antwoordde: „Neen”. De matroos antwoordde: ,Wel, ik zal ze voor je zoeken. Hij vroeg de moeder, wat zij graag zou hebben. De moeder antwoordde; ,,Alles, wat je kan vinden”. De matroos zei gedag en ging heen.

Toen hij in zeker land gekomen was, ging hij zoeken, wat hij kon vinden om voor de moeder te kopen. Hij vond een mooie bloempot, maar de zwarte bloem vond hij niet. Hij was zo bedroefd, omdat hij haar niet kon vinden. Maar op de thuisreis zag hij een zwarte bloem, die groeide aan de oever van de rivier. Hij vroeg, of het schip hem aan wal wilde zetten. Toen hij aan wal gekomen was, nam hij zijn mes om de bloem af te snijden. Op het ogenblik, dat hij haar wilde afsnijden, riep de bloem: ,Wat wil je met me doen?" De matroos antwoordde: ,IIemand heeft me gevraagd een zwarte bloem voor haar te zoeken". De bloem antwoordde: ,Je kunt me afplukken, maar je moet aan die persoon vertellen, dat ik gezegd heb dat, wanneer zij mij wil, zij alles moet aanvaarden, wat haar zal gebeuren."

De matroos beloofde, dat hij dat zou doen.

Toen hij in zijn land teruggekomen was, bracht hij de bloem naar 't meisje en vertelde haar wat de bloem gezegd had. Het meisje schrok, maar toch nam zij haar aan. $\mathrm{Zij}$ zette de bloem in haar slaapkamer op

1) na mi srefi-srefi, 't is ik zelf zelf

$\left.{ }^{2}\right)$ letterlijk: nam haar moeder, om te komen leven met haar 
de vensterbank. 's Avonds, toen zij ging slapen, opende zij naar gewoonte het venster. Juist toen zij was gaan liggen, hoorde zij iets vliegen. $Z$ ij stond op, om te kijken, wat het was. $Z$ ij zag een gans en schrok. De gans veranderde plotseling in een koningskind. Toen sprak hij: „Schrik niet, denk er aan, wat je beloofd hebt"'. Hij babbelde zo gezellig met haar, tot het twaalf uur was; toen veranderde hij weer in een gans en vloog weg. Zo kwam de gans iedere avond, tot hij met haar ging trouwen.

Toen een tante van het meisje te horen kwam, dat zij zou gaan trouwen, ging zij op zekere dag naar haar toe. Toen de moeder van 't meisje de tante zag, zei ze: ,toen ik arm was, kwam je me niet opzoeken". De tante antwoordde: „och, je moet 't zo niet opnemen". De tante bleef de hele dag, maar zij zag de persoon niet, met wie 't meisje zou gaan trouwen.

Op een andere dag stuurde de tante haar kind, om bij haar tante te blijven. 't Meisje bleef de hele dag bij haar tante. 's Nachts bleef ze er slapen ook. Haar moeder had tot haar gezegd, dat zij moest vragen, om bij haar nicht te slapen, want zij moest toezien, of niemand bij haar nicht kwam. 's Avonds vroeg 't kind, om bij haar nicht te mogen slapen. 't Meisje maakte een slaapplaatsje voor haar klaar aan haar hoofdeinde. Op 't ogenblik, dat de gans kwam, sliep 't meisje reeds. 's Morgens werd 't meisje wakker, en ging naar huis. De moeder vroeg haar, wat zij gezien had. Zij antwoordde: , ,ik heb niets gezien, want ik sliep". De moeder was boos op haar en schold haar ontzettend uit.

Een andere dag zond de moeder een ander kind, om bij haar zuster te blijven. Ze zei haar: ,,je moet vragen, om naast je nicht te slapen". 't Kind ging en zei tot haar tante, dat 't 's nachts bleef slapen. 's Avonds vroeg 't kind om naast haar nicht te slapen. 't Meisje legde haar in haar bed. Het kind had een natte doek meegenomen. Iedere keer, wanneer 't slaap kreeg, veegde 't haar ogen met de doek. Zo bleef 't kind wakker, tot 't de gans zag komen. 't Hoorde alles, wat de gans met haar nicht sprak. 's Morgens liep 't kind heel vlug, om aan haar moeder te gaan vertellen, wat 't gezien had. Toen de moeder dat gehoord had, ging zij naar een smid en vroeg hem, of hij een ijzeren pin voor haar kon maken.

Op een keer, in de voornacht, plaatste zij de pin juist waar de gans gewoonlijk neerstreek. 't Meisje en haar moeder wisten niet, dat daar zo iets was.

Toen 's nachts de gans kwam aangevlogen, stak de pin hem, op 't ogenblik, dat hij wilde gaan zitten, onder in zijn buik. Hij werd doodziek. Toen 't meisje bemerkte, dat de gans niet kwam, dacht zij er over na, wat hem wel zou schelen.

Maar's morgens nam de tante de pin weer weg. 't Meisje wachtte vele nachten, maar zag de gans niet meer komen. Zij zei tot haar moeder: „,moeder, ik zal hem gaan opzoeken”.

't Meisje liep en liep, tot zij moe werd; zij zag een boom en ging er onder zitten, om wat uit te rusten. Toen zij daar zat hoorde zij de schildpad tot zijn vriend kakkerlak zeggen: ,'t Koningskind is erg ziek; 't ging naar 't huis van een meisje en toen heeft men een pin geplaatst, om 't te steken. Vele dokters hebben 't reeds bezocht, maar nog steeds kan 't niet beter worden. Maar ik ken een medicijn, die 't beter kan maken"'.

Vriend kakkerlak vroeg: „,wel, welke medicijn is dat?” 
Vriend schildpad antwoordde: ,,je neemt drie bladeren van deze boom en een duivelsstaart, verbrandt ze tot een poeder en smeert dat onder aan de buik van 't koningskind". (De drie bladeren waren van de zwarte bloem).

Toen 't meisje dat hoorde, stond zij zachtjes op, plukte drie bladeren van de boom, zonder dat vriend schildpad en vriend kakkerlak 't bemerkten. Zij ging naar een speelhuis, vroeg vuur, en verbrandde de bladeren en de duivelsstaart. Toen zij daarmee klaar was, vouwde zij 't in een papier tot een poeder. 't Meisje kocht een broek en een jas en trok ze aan. Ze huurde een rijtuig en reed er mee voorbij de deur van 't paleis.

Toen de koning hoorde, dat er een nieuwe dokter voorbij ging, liet hij hem roepen. Aanstonds ging de dokter naar binnen, onderzocht 't koningskind en gaf het de poeder. Daags daarna kwam hij 't weer bezoeken en zag, dat de ziekte afnam. Binnen drie dagen was het koningskind beter. Hij vroeg aan de dokter, hoeveel hij hem moest betalen. De dokter antwoordde: ,,je hoeft me niet te betalen: geef me een zakdoek, waar je naam op gemerkt staat en een vingerring". Maar de koning wilde hem toch geld geven, ofschoon de dokter niet wilde. Maar wat de koning ook deed, hij nam 't niet aan. 't Koningskind gaf hem een ring. Deze nam hij aan en ging toen heel vlug naar huis terug. Toen hij thuis gekomen was, vertelde hij zijn moeder, wat er gebeurd was. De moeder was blij, toen zij hoorde, dat 't koningskind weer beter was.

's Avonds, toen 't meisje ging slapen, hoorde zij, dat de gans kwam aanvliegen. Toen de gans gekomen was, zei hij: ,dat is de beloning, die je me geeft; je had gedacht, dat ik dood zou gaan, maar ik ben al beter geworden." 't Meisje vroeg hem, wat hem gescheeld had. Hij vertelde haar, dat een pin, die zij in 't venster had geplaatst, hem gestoken had. Aanstonds vermoedde ' $t$ meisje, dat haar tante de pin had geplaatst. De gans wilde niets meer van 't meisje weten en weggaan. Maar toen hij weg wilde gaan, vroeg 't meisje hem: ,wel, weet je, wie je genezen heeft?" De gans antwoordde: ,,een dokter".

Toen antwoordde 't meisje: ,Ik in eigen persoon heb je genezen". Maar de gans wilde dat niet geloven.

Omdat hij 't niet wilde geloven nam 't meisje de vingerring en de zakdoek en liet ze hem zien. Toen de gans zag, dat ze van hem waren, schrok hij. 't Meisje vertelde hem, hoe alles gebeurd was.

Toen hij dat hoorde, kwam hij tot de bevinding, dat 't meisje een goed kind was. De gans bleef met haar babbelen tot twaalf uur en ging weer heen.

Thuis gekomen, vertelde hij aan zijn vader, wie de dokter was, die hem had genezen. Aanstonds zei de koning, dat hij met haar moest trouwen. De gans veranderde plotseling in een mens, Hij trouwde met 't meisje en de hele maand vierden zij feest. 't Meisje liet de moeder bij haar inwonen.

En zo eindigt 't verhaal. 
(De SPin, DE Hond EN DE LEVER)

Wan dei konoe takki: „,Meki ${ }^{1}$ mati anansi strei nanga mati dagoe foe njam pepre." Konoe gi ibriwan foe den wan bedi foeloe nanga pepre foe njam. Alla toe kaba a srefi.

Konoe meki den go na kawpen, go teki wan kaw. Anansi fossi teki a teki na kaw nanga na dikki tetei, bikassi a ben denki takki datti na da fattoe kaw, ma datti ben de na mangri kaw. Dagoe teki na fini tetei, ma datti ben de na fattoe kaw. Di mati Anansi si datti, a takki: „,Mi de go leri joe."

Mati Anansi kiri hem kaw, dan a gi mati dagoe wan pisi levre $\left.{ }^{2}\right)$. Mati dago no ben wanni njam hem ete.

Mati Anansi takki: „,Njam hem dan, mati dago”. Mati dago teki ${ }^{3}$ ) a levre poti ${ }^{3}$ ) hem na ondro hem tongo. Mati Anansi denki takki a njam hem kaba, a takki: „Mati dagoe, gi mi mi levre bakka.” Mati dago poeroe ${ }^{4}$ ) a levre foe gi hem bakka, Anansi takki: „,No mati dago, a wan spottoe ${ }^{5}$ ) mi de meki".

Di mati Anansi denki takki mati dagoe sa njam na levre kaba, a takki: „Mati dago, gi mi mi levre bakka”.

Mati dagoe poeroe na levre bakka, a takki: ,Mati anansi teki joe levre bakka".

Ma mati anansi takki: , Njam hem, na spotoe mi de meki”.

Di den wakka so te, watra kiri mati dagoe ${ }^{6}$ ), dan a njam na levre. Den wakka, den wakka so te, dan mati anansi takki: ,,Mati dago, gi mi mi levre bakka".

Mati dago takki: ,we, mi njam hem kaba, joe strefi takki meki mi njam hem, now di mi njam hem kaba, joe wanni hem bakka". Mati anansi takki: ,,So joe sa sabi hofa joe sa sabi hofa joe sa doe, gi mi mi levre bakka".

Mati dago hatti kom bron, a kiri hem kaw, dan a gi mati anansi hem levre bakka. Anansi takki: „A no so wan pikien pisi levre mi ben gi joe”.

Mati dagoe gi hem wan pisi bakka. Di mati dago gi hem datti, anansi takki: ,A no so wan pikien pisi mi ben gi joe”. Mati dagoe gi hem wan trapisi bakka, ma ete a wanni moro. A so a meki a sanni ${ }^{7}$ ) te mati dago gi hem, hem heeri kaw.

Mati dagoe lon gowe a fesi ${ }^{8}$ ), a denki takki: ${ }^{9}$ ) mi sa leri joe". Mati dago go didon na ini wan horo, dan a piri hem tifi na doro $\left.{ }^{10}\right)$. Di mati

1) meki, maken; wordt ook gebruikt voor aanvoegende wijs

${ }^{2}$ ) levre, lever; 't N.E. kent geen $v$, 't woord moet met een $f$ geschreven worden

3) teki poti, letterlijk: nam en plaatste

4) poeroe, letterlijk: wegnemen

5) a wan spottoe, 't is een grap

6) watra kiri mati dagoe, water doodde vriend de hond

7) a meki a sanni, hij maakte de zaak

8) lon gowe a fesi, letterlijk: rende ging weg zijnde gezicht

\%) a denki takki, hij dacht zeggend deur)

$\left.{ }^{10}\right)$ a piri hem tifi na doro, hij schilde zijn tanden naar buiten (zijnde 
anansi kom foe pasa drapee, a si den piri tifi. A takki: „Mi begi gron'ma ${ }^{1}$ ) effi mi kan pasa ${ }^{2}$ )".

Gron'ma takki: ,Hi-hi".

Mati anansi kom frede, a takki bakka: ,,Mi begi, gron'ma, effi mi kan pasa".

Gronmama bari bakka: „Hi-hi”.

Di anansi jeri datti, a teki alla na meti fringi disi gi gronmama, dan a lon gowe na konoe.

Di mati dagoe si, takki mati anansi gowe, a teki hem meti, go foe hem ${ }^{3}$ ) na hoso.

Mati anansi go ferteri kqnoe takki a si gronmama de piri tifi gi hem, dan hem fringi alla hem meti gi hem.

Konoe senni soerdati go loekoe effi na troe. Di den soerdati go, den no si noti. Konoe teki anansi. A fom hem so te, te anansi lon go na ini postoeholo. $\mathrm{Na}$ foe datti hede ${ }^{4}$ ) anansi de tan na ini postoeholo.

\section{Vertaling van}

\section{De Spin, de Hond en de lever}

Op een dag zei Koning: , Laat vriend Spin met vriend Hond wedstrijdhouden in 't peper eten'. Koning gaf ieder van hen een bed vol met peper om op te eten. Alle twee kwamen gelijk klaar.

Koning liet ze naar de koestal gaan om een koe te halen. Spin pakte het eerst. Hij nam de koe met het dikke touw, omdat hij gedacht had, dat dat de vette koe was, maar dat was de magere koe. De hond nam het dunne touw, maar dat was de vette koe. Toen vriend Spin dat zag, zei hij: ,'Ik zal je krijgen”.

Vriend Spin maakte zijn koe dood, daarop gaf hij vriend Hond een stuk lever. Vriend Hond wilde het nog niet opeten.

Vriend Spin zei: ,Eet het maar op, vriend Hond”. Vriend Hond nam de lever, stak hem onder zijn tong. Vriend Spin dacht dat hij hem al opgegeten had, hij zei: "Vriend Hond, geef me mijn lever terug". Vriend Hond haalde de lever tevoorschijn om hem terug te geven. Spin zei : ,Neen, vriend Hond, ik maak een grap."

Toen vriend Spin dacht dat vriend Hond nu wel de lever zou hebben opgegeten, zei hij: ,,Vriend Hond, geef me mijn lever terug”.

Vriend Hond haalde de lever weer tevoorschijn; hij zei : „,Vriend Spin, neem je lever terug".

Maar vriend Spin zei: „Eet hem op, ik maak (maar) een grap”.

Nadat ze heel ver gelopen hadden, kreeg vriend Hond dorst. Toen at

1) gronmama: de geest van de aarde; zo heeft men ook de bosgeest, watergeest, enz.

$\left.{ }^{2}\right)$ effi mi kan pasa, of ik mag passeren

3) go foe hem, letterlijk: ,ging voor hem", zoals men in SurinaamsHollands dikwijls hoort zeggen: de gevoelswaarde van go foe hem is zeer moeilijk weer te geven. Soms heeft 't de betekenis van „maar", zoals in een zin als: mi go foe mi na hosso, ik ga maar naar huis; naar gelang 't verband kan 't ook een andere betekenis hebben

4) na foe datti hede, 't is uit dien hoofde 
hij de lever (door hem per ongeluk in te slikken bij het drinken). Ze liepen en liepen zo ver, toen zei vriend Spin: „Vriend Hond, geef me mijn lever terug"'.

Vriend Hond zei: ,Wel, ik heb hem al opgegeten, je hebt zelf gezegd dat ik hem moest opeten (en) nu ik hem al heb opgegeten, wil je hem terug”. Vriend Spin zei: „Dan zal jij wel weten wat je doet, (maar) geef me mijn lever terug",

Vriend Hond werd kwaad, hij maakte zijn koe dood, daarop gaf hij vriend Spin zijn lever terug. Spin zei: „Het is niet zo'n klein stuk lever geweest, dat ik je gegeven heb".

Vriend Hond gaf hem weer een stuk. Toen yriend Hond hem dat gegeven had, zei de Spin: ,,Het is niet zo'n klein stuk geweest, dat ik je gegeven heb". Vriend Hond gaf hem weer een ander stuk, maar nog wilde hij meer. En zo legde hij het aan, totdat vriend Hond hem zijn gehele koe gaf.

Vriend Hond rende vooruit weg; hij dacht van: ,Ik zal je krijgen.” Vriend Hond ging liggen in een gat; toen liet hij (daar) zijn tanden (alleen) naar buiten grijnzen. Zodra vriend Spin daar kwam om (te) passeren, zag hij de grijnzende tanden. Hij zei: ,'Ik verzoek (u), Grondgeest, of ik mag passeren".

De Grondgeest zei: ,Hi-hi”.

Vriend Spin werd bang, hij zei terug: ,Ik smeek (u), Grondgeest, of ik voorbij mag".

De Grondgeest schreeuwde terug: „Hi-hi”.

Toen Spin dat hoorde, nam hij alle vlees, smeet het voor de Grondgeest, (en) holde daarop naar Koning.

Toen vriend Hond zag dat vriend Spin weg was, nam hij zijn vlees en ging wat hem betrof naar huis.

Vriend Spin ging Koning vertellen, dat hij de Grondgeest tegen hem had zien tanden-grijzen, daarop had hij al zijn vlees voor haar gesmeten.

Koning zond soldaten om te kijken of het waar (was). Toen de soldaten gingen, zagen ze niets. Koning greep Spin. Hij ranselde hem zo zeer, tot Spin wegrende in een beslagruimte. Uit dien hoofde verblijft "de" spin in de beslagruimten.

\section{S U M M A R Y}

\section{ON THE LANGUAGE AND THE TALES OF SURINAME}

Father Donicie is a missionary in Dutch Guiana. The following is a brief digest of his article.

The so-called Negro-English is made up of African elements as well as English and Dutch, with a few vestiges of Portuguese and French. The Surinamese language hardly has any written literature. Many of the traditional stories which are handed down orally have been transcribed by Moravian and Dutch missionaries and by a few research workers.

An analysis of the language of Suriname can thus best be made by looking for its structure in the old folk-tales, although the transcriptions otfer difficulties as to the phonestic systems used.

The author bases his analysis on a number of tales collected by Fafher AHLBRINCK in 1912. 
From these and other collections (van Cappelle, Herskovits), he shows that about half of the tales are concerned with Anansi, the spider. The influence of European fairy tales on Surinamese folklore has hardly been studied as yet. Anansi certainly originates in Africa and may be considered as one of the gods of death and of fertility (sun-symbol). Father Donicie states that the custom of telling tales as bed-time stories is disappearing, but that on the eve of a burial anansi-stories are still widely in use (dede-hoso: dead house) and also amongst the balatableeders in the bush.

He quotes a lively description by CAMPAGNE of the way in which stories are told in the evening, not only about the spider, but adaptations of the Arabian Nights, and riddles and special interrupting songs as well.

In order to give the reader a feeling of the simple atmosphere of the tales Father DoNicie explains some of the linguistic rules, the sound system and the syntax. Western European language categories are not applicable to Surinamese, but the author has to use them for the sake of European trained readers.

He then proceeds to give a full text and a dutch translation of The Goose and the Girl and The Spider, the Dog and the Piece of Liver.

\section{B E S P R E K I N G}

Het Rijksdeel Suriname, door Mr J. C. Brons. V.U.B. 2e reeks no. 44, Haarlem, 1952, 214 blz., 1 kaartje $(f 3,90)$.

Het is tekenend dat het tot 1952 moest duren voor en aleer de in 1920 begonnen Volks Universiteits Bibliotheek een deeltje over WestIndië kon uitgeven. Populair-wetenschappelijk in de beste zin is ook dit boekje Het Rijksdeel Suriname. Mr BroNs heeft in ruim 200 bladzijden vrijwel alles gegeven wat over Suriname te weten valt. En, gelukkig, met de nadruk op het actuele: de na-oorlogse ontwikkeling, aan welke de schrijver als gouverneur in de eerste jaren na 1945 mede leiding gaf, krijgt het volle pond. Feitelijk en objectief worden de verschillende aspecten van Suriname behandeld: land en volk, geschiedenis, recente sociaal economische en staatkundige ontwikkeling, godsdiensten, onderwijs en cultuur, volksgezondheid, bestuur en rechtspraak, landbouw c.a., bossen, mijnbouw, industrie en verkeer en tenslotte internationale samenwerking.

Enige bevolkingscijfers, een literatuuropgave, index en een kaartje vergemakkelijken de raadpleging als encyclopaedie in zakformaat. De uitgeefster zou de gebruikers met een betere kaart zeker een goede dienst hebben bewezen. Immers dit boekje is vooral bestemd voor mensen die van Suriname weinig afweten en van wier voorstellingsvermogen nu wel veel gevergd wordt. Degenen die bepaalde details willen opzoeken kunnen de schrijver dankbaar zijn voor het vele dat hij in klein bestek heeft samengebracht. Slechts een heel en kele slip of the pen (b.v. Kwakoegrom voor Kabel, p. 193/194) misstaat bij deze ambtelijke accuratesse.

J. F. K 